\title{
New approaches to management of neonatal hypoglycemia
}

\author{
Paul J. Rozance ${ }^{*}$ and William W. Hay Jr.
}

\begin{abstract}
Despite being a very common problem after birth, consensus on how to manage low glucose concentrations in the first $48 \mathrm{~h}$ of life has been difficult to establish and remains a debated issue. One of the reasons for this is that few studies have provided the type of data needed to establish a definitive approach agreed upon by all. However, some recent publications have provided much needed primary data to inform this debate. These publications have focused on aspects of managing low blood glucose concentrations in the patients most at-risk for asymptomatic hypoglycemia - those born late-preterm, large for gestational age, small for gestational age, or growth restricted, and those born following a pregnancy complicated by diabetes mellitus. The goal of this review is to discuss specific aspects of this new research. First, we focus on promising new data testing the role of buccal dextrose gel in the management of asymptomatic neonatal hypoglycemia. Second, we highlight some of the clinical implications of a large, prospective study documenting the association of specific glycemic patterns with neurodevelopmental outcomes at two years of age.
\end{abstract}

Keywords: Neonatal hypoglycemia, Dextrose gel, Continuous glucose monitoring, Infant of a diabetic mother, Late preterm, Small for gestational age, Large for gestational age, Intrauterine growth restriction

\section{Background}

Hypoglycemia is one of the most frequently encountered problems in the first $48 \mathrm{~h}$ of life, and low glucose concentrations are perhaps the most common biochemical abnormality seen by providers caring for newborns. Unfortunately, the optimal strategy for managing this problem remains elusive and is a matter of differing interpretations of the available literature [1-8]. New data to inform the optimal management of these newborns is urgently needed [9]. Especially controversial is the management of asymptomatic but at-risk newborns, most commonly those with a history or physical exam consistent with being born late-preterm, large for gestational age (LGA), small for gestational age (SGA), or growth restricted, or an infant of a diabetic mother (IDM). The reason for this controversy is that numerous studies have shown that, with the exception of the LGA group, these newborns have worse neurodevelopmental outcomes than healthy term babies [10-13] and that in some of these groups, worse neurodevelopmental outcomes are associated

\footnotetext{
* Correspondence: Paul.Rozance@ucdenver.edu

Perinatal Research Center, Department of Pediatrics, University of Colorado School of Medicine, 13243 E 23rd Ave, MS F441, Aurora, CO 80045, USA
}

with the presence of neonatal hypoglycemia [12]. To date, no study has shown that preventing or treating the hypoglycemia in these groups leads to better outcomes, making it uncertain whether hypoglycemia has a causal role in producing the worse outcomes. In fact, the statement made by the AAP in 1993 remains accurate today, "... there is no evidence that asymptomatic hypoglycemic infants will benefit from treatment [14]." The goal of this review is to discuss recent primary research that has added important new data to consider when devising strategies to manage this group of newborns. These recent data hold promise for optimizing our approach to managing neonatal hypoglycemia, especially in the at-risk groups noted above.

\section{Asymptomatic neonatal hypoglycemia}

The newborns most at risk for, and most frequently screened for, asymptomatic hypoglycemia include late preterm, LGA, SGA, and/or intrauterine growth restricted (IUGR) infants, and IDMs [4]. Frequent milk feedings with repeated glucose measurements is the current standard treatment for asymptomatic hypoglycemia in these groups of patients [4]. This approach allows mothers and babies to remain together, provides nutrient substrates 
to support gluconeogenesis as it develops, and ensures that the hypoglycemia resolves. If hypoglycemia persists despite frequent milk feedings, a continuous intravenous dextrose infusion may be indicated. The following approach to the rate of dextrose infusion for asymptomatic hypoglycemia can be considered. A dextrose infusion rate of $3-5 \mathrm{mg} / \mathrm{kg} /$ min can be used for IDMs, as this avoids overstimulation of insulin secretion and accounts for the larger fat mass that these infants have. A dextrose infusion rate of $4-7 \mathrm{mg} / \mathrm{kg} /$ min can be used for most term and near term infants. A dextrose infusion rate of $6-8 \mathrm{mg} / \mathrm{kg} / \mathrm{min}$ often is necessary in IUGR infants. This accounts for their greater brain/body weight ratio and physiological observations made in animal models of IUGR of both increased peripheral insulin sensitivity and increased insulin secretion as their postnatal physiology is normalized and insulin-suppressive catecholamine secretion is reduced [15-20]. Glucose concentrations must be followed closely as some of these IUGR infants, especially those very preterm, also can have hyperglycemia, due to reduced insulin secretion capacity, diminished muscle mass for glucose disposal, and persistent glucose production [17, 18, 20-30]. A continuous intravenous dextrose infusion, usually preceded by an intravenous dextrose bolus (200 $\mathrm{mg} / \mathrm{kg}$ given over $5 \mathrm{~min}$ ), also is indicated if these newborns develop symptomatic hypoglycemia. In fact, partial or complete resolution of the symptoms with correction of glucose concentrations is considered proof that the symptoms were caused by the low glucose concentrations [31]. Intravenous dextrose infusions, however, are not benign; they cause discomfort and stress due to the placement of an intravenous catheter, admission to a NICU, and physical separation of the mother and newborn which risks impairing the timely and successful establishment of breastfeeding and bonding. Preventing these complications of intravenous dextrose infusions, while safely managing asymptomatic low glucose concentrations, has many potential benefits.

\section{Dextrose gel}

To this end, Harris, et al. undertook a large, randomized, placebo-controlled, double-blinded study of buccal dextrose gel for the treatment of asymptomatic hypoglycemia, defined as a plasma glucose less than $47 \mathrm{mg} / \mathrm{dL}$ $(2.6 \mathrm{mmol} / \mathrm{L})$ irrespective of postnatal age [32]. The dextrose gel $(200 \mathrm{mg} / \mathrm{kg})$ or placebo gel was massaged into the infant's dried buccal mucosa and the infant was encouraged to feed. If the baby still had a low glucose concentration $30 \mathrm{~min}$ after gel administration, or if the baby developed recurrent hypoglycemia, the treatment with study gel continued for a total of six doses over $48 \mathrm{~h}$. The specific characteristics of the populations studied included late preterm (35-36 weeks gestational age), LGA ( $>90$ th percentile or $>4500 \mathrm{~g})$, SGA/IUGR $(<10$ th percentile or $<2500 \mathrm{~g}$ ), and IDM newborns. In these groups dextrose gel decreased the number of episodes of hypoglycemia, decreased the recurrence rate of hypoglycemia, increased exclusive breastfeeding rates at discharge, and decreased the need for admission to the neonatal intensive care (NICU) unit to treat hypoglycemia. The number of newborns needed to treat to prevent one admission to the NICU for hypoglycemia was only eight. It is important to note that in this study the newborns, regardless of randomization, were still managed with aggressive oral feeding (mostly breastmilk) to treat hypoglycemia. There were no adverse events reported and continuous interstitial glucose monitoring (to which the care providers were blinded) did not identify more frequent, clinically unrecognized episodes of rebound or recurrent hypoglycemia in the dextrose gel group, thereby establishing short term safety. Of note, overall admission rates to the NICU for all causes were not statistically significantly different between groups (38 \% in the dextrose gel group vs. $46 \%$ with placebo gel). The most likely cause of the lack of effect on overall NICU admission rates, despite the reduction in NICU admissions to treat hypoglycemia, is simply that the sample size was too small to show a difference in this secondary outcome.

Despite these encouraging short term results, there was some concern that the dextrose gel treatment might have adversely impacted long term neurodevelopmental outcomes. Reasons for concern included a potential delay in definitive treatment with intravenous dextrose, rapid overcorrection and iatrogenic hyperglycemia, and increased variability in glucose concentrations [33, 34]. Information from continuous glucose monitoring sensors (CGMS), which was blinded to the caregivers, was reassuring regarding these concerns. When the researchers looked at the CGMS data, however, they found that the time to achieve an interstitial glucose concentration greater than $47 \mathrm{mg} / \mathrm{dL}(2.6 \mathrm{mmol} / \mathrm{L})$ with dextrose gel was as rapid as has been reported for correction with intravenous dextrose given at $8 \mathrm{mg} / \mathrm{kg} / \mathrm{min}$-about twenty minutes [35]. CGMS data also showed that rebound hypoglycemia was rare in both groups and the incidence of recurrent hypoglycemia was less in the dextrose gel group. While these data support the safety and efficacy of he dextrose gel established by intermittent glucose sampling, CGMS was only used in a subset of the patients in this study. Therefore, it is important that two year outcomes have recently been published [36]. $78 \%$ of the original hypoglycemic cohort was available for assessment of outcomes at two years of age. Fortunately, there were no differences between the dextrose gel group and placebo group for neurosensory impairment, processing difficulties, or secondary growth and developmental outcomes. The high rates of abnormal outcomes in both groups is concerning and should 
prompt further research into optimal management of these patients [36].

When considering the adoption of dextrose gel into clinical practice, it must be remembered that although the study was quite large and included a broad representation of the main at-risk groups, it was a single center study. A multi-centered trial confirming these results would broaden the applicability of this therapy. This issue is highlighted by the results for improved rates of exclusive breast feeding at two weeks of age [32]. The rates of exclusive breastfeeding at this age are quite high in this New Zealand population. Whether this benefit would be replicated in populations with higher or lower rates of breast feeding is unknown. However, if a new trial included hospitals without a NICU, the benefits of dextrose gel might also include lower transfer rates of these patients to hospitals that have intensive care capabilities. It also is important to note that the definition of hypoglycemia and treatment cut-off were both $47 \mathrm{mg} /$ $\mathrm{dL}(2.6 \mathrm{mmole} / \mathrm{L})$, irrespective of gestational and postnatal age. This definition does not take into account the age related changes in mean and lower limits of normal glucose concentrations that occur in the first days of life [37]. The definition of hypoglycemia, screening frequency, and screening duration also may vary from what is used in some clinical practices $[4,8]$. Clinicians should ensure that they have accounted for these differences when considering adoption of dextrose gel into clinical practice. Not only was screening for hypoglycemia quite frequent, in this study the clinicians used a very reliable point of care device. This device uses the gold standard glucose oxidase method for measurement of plasma glucose concentrations, which is much more accurate than bedside glucometers [38]. Glucose concentrations were measured at one hour of age, then before feeds every $3-4 \mathrm{~h}$ for the first $24 \mathrm{~h}$ of age, and then before feeds every $6-8 \mathrm{~h}$ for the next $24 \mathrm{~h}$. This protocol identified $46 \%$ of the enrolled patients as hypoglycemic, who were included in the study. This relatively high incidence of neonatal hypoglycemia in this population likely is due to the rigorous and frequent screening protocol, the method used to measure glucose concentrations, the higher glucose concentration threshold that was used to define hypoglycemia compared to other published guidelines [4], and a definition of hypoglycemia that does not exclude infants who have low glucose concentrations during the normal physiological nadir that occurs in normal infants in the first hours of life $[7,37]$.

Other important considerations are that the dextrose gel treatment was tested in infants who were at-risk for hypoglycemia but were otherwise well-appearing and asymptomatic [32]. The results cannot be applied to infants with severe, symptomatic, and recurrent hypoglycemia, and/or if the infant is not in one of the at-risk groups studied. Furthermore, the dextrose gel did not eliminate the need for intravenous dextrose therapy. Over $10 \%$ of infants treated with dextrose gel in this study had an episode of rebound hypoglycemia and over $20 \%$ had an episode of recurrent hypoglycemia after a documented normal glucose concentration. While these rates were similar to or better than those in the placebo group, practitioners should not be using this therapy without close follow up of subsequent glucose concentrations, clinical signs of hypoglycemia, and documentation of resolution of the hypoglycemia $[4,8]$. Despite these limitations, the therapy appears safe and effective at preventing NICU admissions for hypoglycemia and it may be appropriate for some hospitals to adopt into clinical practice. Indeed, such efforts are already being described with promising results [39, 40]. Making guidelines for managing low glucose concentrations in the first days of life safe and easy to follow, while at the same time promoting increased maternal-infant interactions and increased breastfeeding rates, is critical for all practitioners caring for newborns. Buccal dextrose gel appears to have a promising role in achieving these goals and caregivers can be more confident that the early benefits of dextrose gel are not associated with worse two year neurodevelopmental outcomes [36].

\section{Continuous glucose monitoring}

Another interesting feature of the dextrose gel study is the use of CGMS to continuously monitor interstitial glucose concentrations. One important observation is that many episodes of hypoglycemia, documented by both blood obtained per their low glucose concentration screening protocol and CGMS measurements, resolved spontaneously, and were not associated with bedside nursing observations of clinical signs that might be interpreted as symptoms of hypoglycemia. Thus, while CGMS remains a research tool, this observation demonstrates the potential for CGMS to reduce unnecessary treatment for hypoglycemia. For example, CGMS may identify patients in whom their low glucose concentrations have resolved prior to commencement of interventions. However, there also is the potential for CGMS to increase unnecessary treatment for hypoglycemia. For the clinician, CGMS or any other method that continuously provides glucose concentration data will present a challenge to the way we think about hypoglycemia. Instead of an intermittent variable, caregivers will be provided with a continuous variable, analogous to the transition from intermittent blood gas measurements to continuous pulse oximetry for monitoring blood oxygenation. Furthermore, CGMS in this population, as well as in more preterm newborns, will identify numerous episodes of low glucose concentrations that are not identified by intermittent routine blood sampling [41, 42]. In 
fact, in the populations studied by Harris, et. al., $81 \%$ of all episodes of hypoglycemia were recognized with CGMS only and not by routine clinical blood sampling [42]. There is very little information about the clinical significance of these episodes for long term outcomes, including which should be treated and whether such treatment would improve outcomes. It is possible, therefore, that identifying these episodes of hypoglycemia with CGMS could increase overtreatment of clinically insignificant low glucose concentrations. This risk might outweigh the benefits of documenting more episodes of low glucose concentrations and avoiding treatment of those that resolve spontaneously, as well as the early detection of serious, recurrent hypoglycemia in patients with hyperinsulinemic hypoglycemia and other metabolic disorders [43]. The uncertainty regarding the balance of the risks and benefits of using CGMS or similar devices for the continuous monitoring of neonatal glucose concentrations in this population highlights the need for further studies in this area. Such studies will have to be designed to clarify relationships between continuous glucose concentrations, symptomatic hypoglycemia, responses to treatment, associated medical conditions, and neurodevelopmental outcomes.

\section{Identifying and treating asymptomatic hypoglycemic newborns}

There is very little evidence to inform how often glucose concentrations should be screened in the asymptomatic at-risk newborn or the glucose concentration threshold one should use for treatment. Also unknown are the degree and duration of hypoglycemia necessary to cause permanent neurological injury [9]. Especially important is the question of how to identify the rare infant in which asymptomatic hypoglycemia is the first presentation of a rare and persistent disorder of hypoglycemia such as congenital hyperinsulinemic hypoglycemia, fatty acid oxidation disorders, hypopituitarism, and glycogen storage diseases [8]. In 2011 the AAP published clinical guidelines to address some of these concerns, with special attention to management of hypoglycemia in the first $24 \mathrm{~h}$ of life [4]. They suggested that late preterm, LGA, SGA/IUGR, and IDM newborns should be fed by one hour of age and have their glucose checked $30 \mathrm{~min}$ after the feeding. Glucose monitoring should then continue before feeds through $12 \mathrm{~h}$ of age for LGA and IDM patients as long as pre-feed plasma glucose concentrations remain greater than $40 \mathrm{mg} / \mathrm{dL}(2.2 \mathrm{mmol} / \mathrm{L})$. It was suggested that late preterm and SGA infants should be screened before feeds for $24 \mathrm{~h}$. In 2012 Harris, et al. published the incidence of hypoglycemia during this same $24 \mathrm{~h}$ period, again defining as plasma glucose concentrations $<47 \mathrm{mg} / \mathrm{dL}(2.6 \mathrm{mmol} / \mathrm{L})$ irrespective of age in this same group of newborns [44]. They used a more frequent screening protocol, measuring glucose concentrations one hour after birth and then before feeds every $3-4 \mathrm{~h}$ for the first $24 \mathrm{~h}$ of life, but also added screening every 3-8 $\mathrm{h}$ for the second $24 \mathrm{~h}$ of life. While the incidence of hypoglycemia in this population was quite high (51\%), more important were the observations that, of the patients with hypoglycemia, $37 \%$ had their first episode after having had three plasma glucose concentrations greater than $47 \mathrm{mg} / \mathrm{dL}(2.6 \mathrm{mmol} / \mathrm{L})$ and $6 \%$ had their first episode after $24 \mathrm{~h}$ of age [44]. Another important observation in this study was that there were no differences among the at-risk groups studied in the incidence or timing of the hypoglycemia. While the long term clinical significance of these episodes of hypoglycemia, whether first identified in the first $24 \mathrm{~h}$ or later, remains unclear, it may be a reasonable approach to simplify screening protocols so that screening frequency and duration are the same for all atrisk groups $[44,45]$.

The definition of hypoglycemia and the threshold for treatment and continued management are controversial as well. A plasma glucose concentration of $47 \mathrm{mg} / \mathrm{dL}(2.6 \mathrm{mmol} / \mathrm{L})$ was used in multiple studies by Harris, et al. as their threshold for diagnosis and treatment [32, 34, 36, 42, 44]. The 2011 guideline by the AAP states that once hypoglycemia is identified, treatment should commence with feeding or intravenous dextrose infusion and a target plasma glucose concentration of greater than $45 \mathrm{mg} / \mathrm{dL}(2.5 \mathrm{mmol} / \mathrm{L})$ should be used [4]. In 2015 the Pediatric Endocrine Society published new recommendations regarding the management of hypoglycemia in newborns [8]. While the main goals of these recommendations were to help clinicians distinguish between physiologically low glucose concentrations in normal newborns and those that persist beyond the first $48 \mathrm{~h}$ of life and might place the infant at risk for neurological injury, this group made the recommendation that in the first $48 \mathrm{~h}$ of life the target threshold plasma glucose concentration for treatment should be $50 \mathrm{mg} / \mathrm{dL}(2.8 \mathrm{mmol} / \mathrm{L})$. This group also made the case that neurogenic symptoms occur in newborns below the same glucose concentrations as in adults $(55-65 \mathrm{mg} / \mathrm{dL}$ [3.1-3.6 mmol/L]) [7, 8]. Thus, they also make the recommendation that in specific patients higher glucose target thresholds of $60 \mathrm{mg} / \mathrm{dL}$ $(3.3 \mathrm{mmol} / \mathrm{L})$ and $70 \mathrm{mg} / \mathrm{dL}(3.9 \mathrm{mmol} / \mathrm{L})$ should be used [8]. To date, there is no data to rationally define selection of any one of these lower limit threshold glucose concentration values, in terms of which treatment to use, acute risks vs. benefits, or impact on longer term neurodevelopmental outcomes.

The variability among the recommendations of these different publications reflects the need for further research. A recent publication from the same group that 
performed the dextrose gel study has provided some data [34], but this was not a study that randomized newborns to different glucose treatment thresholds. However, what they found was that, regardless of treatment with or without the dextrose gel, asymptomatic patients in the main at-risk groups (late preterm, LGA, SGA/ IUGR, IDM) had similar neurodevelopmental outcomes at two years of age whether they had hypoglycemia $(<47 \mathrm{mg} / \mathrm{dL}[2.6 \mathrm{mmol} / \mathrm{L}])$ identified in the first seven days of life or not [34]. This assumes that the infants were screened in the first $48 \mathrm{~h}$ by the rigorous protocol described above and that when identified, the newborns were treated to achieve or exceed a target plasma glucose concentration of $47 \mathrm{mg} / \mathrm{dL}(2.6 \mathrm{mmol} / \mathrm{L})$. The main conclusion that one can make from these data is that in this specific patient population with frequent screening and identification of hypoglycemia, using a target plasma glucose concentration of $47 \mathrm{mg} / \mathrm{dL}(2.6 \mathrm{mmol} / \mathrm{L})$ results in neurodevelopmental outcomes similar to those at-risk patients who did not have an episode of hypoglycemia [34]. However, it cannot be emphasized enough that the plasma glucose concentration defining hypoglycemia was arbitrarily set at $47 \mathrm{mg} / \mathrm{dL}(2.6 \mathrm{mmol} / \mathrm{L})$ and does not take into account evolution of glucose concentrations and their variability in the first week of life [7]. A plasma glucose concentration of $47 \mathrm{mg} / \mathrm{dL}(2.6 \mathrm{mmol} / \mathrm{L})$ will likely be less clinically relevant at $6 \mathrm{~h}$ of age compared to four days of age, when low glucose concentrations should have increased spontaneously [7].

In the study by McKinlay, et al. the rate of neurodevelopmental delay was not different in the group that experienced a hypoglycemic event (33\%) compared to the group that did not (36\%) [34]. But these rates are high, and some might argue that the threshold for treatment should be even higher than $47 \mathrm{mg} / \mathrm{dL}(2.6 \mathrm{mmol} / \mathrm{L})$. However, the lack of two year neurodevelopmental outcome data in a concurrently tested group of healthy term control children makes this conclusion premature. It could be that the novel and highly sophisticated techniques that were used to detect abnormal outcomes are so sensitive as to give a high false positive rate and that if a group of healthy term control infants were tested at the same time, they too would have unexpectedly high rates of abnormal outcomes. More importantly, there are significant risks to a more aggressive screening and treatment strategy. These include increased frequency of blood sampling, use of formula supplementation, admission to the NICU and separation from the mother, complications of intravenous catheters, and side effects of any therapies used to raise glucose concentrations. These risks must be balanced against the potential harm due to asymptomatic hypoglycemia, progression to symptomatic hypoglycemia, and delay in diagnosis and treatment of serious metabolic disorders.
The authors also noted three important associations in their data that should provide some caution with respect to increasing glucose treatment thresholds and goals. One is that newborns who did not have a plasma glucose lower than $54 \mathrm{mg} / \mathrm{dL}(3.0 \mathrm{mmol} / \mathrm{L})$ had worse outcomes than those newborns who did. By CGMS data, the average difference in glucose concentrations between those with worse outcomes and those with better outcomes was only $2.9 \mathrm{mg} / \mathrm{dL}(0.16 \mathrm{mmol} / \mathrm{L})$. A second important association noted was that those newborns who had more time with plasma glucose concentrations outside the range of $54-72 \mathrm{mg} / \mathrm{dL}(3.0-4.0 \mathrm{mmol} / \mathrm{L}) \mathrm{did}$ worse in terms of the highly sensitive neurodevelopmental outcomes than those who had more time within this concentration range. Clearly, these first two associations are in conflict if one were to attempt to change clinical practice based on these observations. Most likely these conflicting associations show that sicker neonates are more metabolically unstable and have worse two year neurodevelopmental outcomes, not that the increased glucose concentration variability necessarily caused the worse outcomes - though this possibility cannot be excluded.

The final important association identified is that, of the hypoglycemic newborns, those with worse outcomes had a steeper rise in their glucose concentrations after treatment with dextrose. This brings up the possibility that in these at-risk asymptomatic newborns with low glucose concentrations, when one decides to commence therapy with intravenous dextrose, it is reasonable to simply start the patient on a continuous glucose infusion rate and not precede this with the traditional $200 \mathrm{mg} / \mathrm{kg}$ intravenous dextrose bolus. Previous studies have shown that within 20-30 min hypoglycemic newborns treated without the $200 \mathrm{mg} / \mathrm{kg}$ bolus dextrose and only a continuous infusion of dextrose achieve glucose concentrations similar to those treated with the dextrose bolus followed by the same continuous dextrose infusion rate [35]. Given that no study has shown that treatment of asymptomatic hypoglycemia in these patients, no matter how rapid, improves outcomes, it seems that avoiding the steeper rise in glucose concentrations which were associated with worse outcomes in the McKinlay, et al. study is warranted. Other important points to consider when evaluating this study are that severe and symptomatic hypoglycemia was rare. Similarly, hyperglycemia also was rare, as only three patients had a plasma glucose concentration greater than $144 \mathrm{mg} / \mathrm{dL}(8 \mathrm{mmol} / \mathrm{L})$. It also should be emphasized again that the only patients studied were those who were asymptomatic and late preterm, LGA, SGA/IUGR, and IDM infants [34]. The conclusions, including the abandonment of the $200 \mathrm{mg} /$ $\mathrm{kg}$ dextrose bolus, cannot necessarily be extrapolated to other groups, especially those with symptomatic 
Table 1 Recommendations for the management of neonatal hypoglycemia

1. Buccal dextrose gel should be considered as part of a strategy for managing asymptomatic neonates with low glucose concentrations.

2. For asymptomatic neonates with low glucose concentrations requiring intravenous dextrose, bolus glucose infusions may be replaced by simply starting the patient on a continuous dextrose infusion.

3. Continuous glucose monitoring should be considered in research protocols to assess the benefits and risks of different glycemic patterns for outcomes.

hypoglycemia or a defined or suspected serious metabolic hypoglyyemia disorder, such as congenital hyperinsulinemic hypoglycemia or genetic conditions that lead to excessive glucose utilization (fatty acid oxidation disorders) or insufficient glucose production (hypopituitarism). Nevertheless, abandoning the dextrose bolus might be beneficial in infants of diabetic mothers and those with hyperinsulin-like conditions who respond to rapid increases in glucose concentration with excessive insulin secretion, potentially establishing a rebound hypoglycemia if the continuous dextrose infusion is not high enough.

\section{Conclusions}

Unfortunately, no recently published studies define one ideal strategy to diagnose and appropriately treat potentially damaging low glucose concentrations in neonates. In order to determine the best management strategy, a randomized trial comparing two different strategies with appropriate long term follow up is required, as proposed by Boluyt, et al. in 2006 [46]. Continued use of CGMS as a research tool to demonstrate the impact of different glycemic patterns on long term outcomes in hypoglycemia newborns will be very helpful in this type of study $[34,43]$. However, short of this type of study we can look at recently published information and consider two potential changes in how neonatal hypoglycemia is managed (Table 1). One is consideration of dextrose gel as part of a treatment protocol for neonatal hypoglycemia. The second is abandonment of the $200 \mathrm{mg} / \mathrm{kg}$ intravenous dextrose bolus for the treatment of asymptomatic, hypoglycemic late preterm, LGA, SGA/IUGR, and IDM newborns.

\section{Abbreviations}

CGMS: Continuous glucose monitoring sensor; IDM: Infant of a diabetic mother; IUGR: Intrauterine growth restriction; LGA: Large for gestational age; SGA: Small for gestational age.

\section{Competing interests}

The authors declare that they have no competing interests.

\section{Authors' contributions}

PJR wrote the first draft of the manuscript. PJR and WWH conceived of the review, edited the manuscript and approved the final version.

\section{Acknowledgements}

The authors would like to thank Dr. Laura Brown for insightful discussions regarding the content of this manuscript.

The article is a review of very recent publications regarding the management of neonatal hypoglycemia. The new data focus on asymptomatic hypoglycemia in late preterm babies, IDM's, IUGR/SGA babies and LGA babies. More specifically, the use of dextrose gel in the management of these infants and the potential for worse outcomes with over aggressive correction of hypoglycemia are discussed. We have considered these new data in the context of previous publications and recommendations. We make some recommendations to clinicians regarding implementation of new strategies for the management of neonatal hypoglycemia taking into account these new data.

\section{Declarations}

Dr. Rozance has a consulting relationship with Xoma Corporation.

\section{Funding}

PJR is supported by NIH Grants R01 DK088139 (PJR PI; WWH Co-l) and WWH is supported by NIH Grants T32 HD007186 (WWH PI and PD) and NIH K12 HD068372 (MWH, PD). The content is solely the responsibility of the authors and does not necessarily represent the official views of the NIDDK or NICHD.

Received: 17 March 2016 Accepted: 19 April 2016

Published online: 10 May 2016

\section{References}

1. Boardman JP, Wusthoff CJ, Cowan FM. Hypoglycaemia and neonatal brain injury. Arch Dis Child Educ Pract Ed. 2013;98:2-6.

2. Hawdon JM. Definition of neonatal hypoglycaemia: time for a rethink? Arch Dis Child Fetal Neonatal Ed. 2013;98:F382-3.

3. Rozance PJ, Hay WW. Hypoglycemia in newborn infants: features associated with adverse outcomes. Biol Neonate. 2006;90:74-86.

4. Adamkin DH. Postnatal glucose homeostasis in late-preterm and term infants. Pediatrics. 2011;127:575-9.

5. Adamkin DH. Neonatal hypoglycemia. Curr Opin Pediatr. 2016;28:150-5.

6. Adamkin DH, Polin R. Neonatal hypoglycemia: is 60 the new 40? The questions remain the same. J Perinatol. 2016;36:10-2.

7. Stanley CA, Rozance PJ, Thornton PS, De Leon DD, Harris D, Haymond MW, Hussain K, Levitsky LL, Murad MH, Simmons RA, Sperling MA, Weinstein DA, White NH, Wolfsdorf Jl. Re-evaluating "transitional neonatal hypoglycemia": mechanism and implications for management. J Pediatr. 2015;166:1520-5.

8. Thornton PS, Stanley CA, De Leon DD, Harris D, Haymond MW, Hussain K, Levitsky LL, Murad MH, Rozance PJ, Simmons RA, Sperling MA, Weinstein DA, White NH, Wolfsdorf JI. Recommendations from the Pediatric Endocrine Society for Evaluation and Management of persistent hypoglycemia in neonates, infants, and children. J Pediatr. 2015;167:238-45.

9. Hay Jr WW, Raju TN, Higgins RD, Kalhan SC, Devaskar SU. Knowledge gaps and research needs for understanding and treating neonatal hypoglycemia: workshop report from Eunice Kennedy Shriver National Institute of Child Health and Human Development. J Pediatr. 2009;155:612-7.

10. Arcangeli $T$, Thilaganathan B, Hooper R, Khan KS, Bhide A. Neurodevelopmental delay in small babies at term: a systematic review. Ultrasound Obstet Gynecol. 2012;40:267-75.

11. Brand PL, Molenaar NL, Kaaijk C, Wierenga WS. Neurodevelopmental outcome of hypoglycaemia in healthy, large for gestational age, term newborns. Arch Dis Child. 2005;90:78-81.

12. Stenninger E, Flink R, Eriksson B, Sahlen C. Long-term neurological dysfunction and neonatal hypoglycaemia after diabetic pregnancy. Arch Dis Child Fetal Neonatal Ed. 1998;79:F174-9.

13. von Beckerath AK, Kollmann M, Rotky-Fast C, Karpf E, Lang U, Klaritsch P. Perinatal complications and long-term neurodevelopmental outcome of infants with intrauterine growth restriction. Am J Obstet Gynecol. 2013:208:130-6.

14. American Academy of Pediatrics Committee on Fetus and Newborn. Routine evaluation of blood pressure, hematocrit, and glucose in newborns. Pediatrics. 1993;92:474-6.

15. Barry JS, Rozance PJ, Brown LD, Anthony RV, Thornburg KL, Hay WW Jr. Increased fetal myocardial sensitivity to insulin-stimulated glucose metabolism during ovine fetal growth restriction. Exp Biol Med (Maywood). 2016. [Epub ahead of print]. 
16. Leos RA, Anderson MJ, Chen X, Pugmire J, Anderson KA, Limesand SW. Chronic exposure to elevated norepinephrine suppresses insulin secretion in fetal sheep with placental insufficiency and intrauterine growth restriction. Am J Physiol Endocrinol Metab. 2010;298:E770-8.

17. Limesand SW, Rozance PJ, Zerbe GO, Hutton JC, Hay Jr WW. Attenuated insulin release and storage in fetal sheep pancreatic islets with intrauterine growth restriction. Endocrinology. 2006;147:1488-97.

18. Limesand SW, Rozance PJ, Smith D, Hay Jr WW. Increased insulin sensitivity and maintenance of glucose utilization rates in fetal sheep with placental insufficiency and intrauterine growth restriction. Am J Physiol Endocrinol Metab. 2007;293:E1716-25.

19. Macko AR, Yates DT, Chen X, Green AS, Kelly AC, Brown LD, Limesand SW. Elevated plasma norepinephrine inhibits insulin secretion, but adrenergic blockade reveals enhanced beta-cell responsiveness in an ovine model of placental insufficiency at 0.7 of gestation. J Dev Orig Health Dis. 2013:4:402-10.

20. Thorn SR, Brown LD, Rozance PJ, Hay Jr WW, Friedman JE. Increased hepatic glucose production in fetal sheep with intrauterine growth restriction is not suppressed by insulin. Diabetes. 2013;62:65-73.

21. Brown LD, Rozance PJ, Thorn SR, Friedman JE, Hay Jr WW. Acute supplementation of amino acids increases net protein accretion in IUGR fetal sheep. Am J Physiol Endocrinol Metab. 2012;303:E352-64.

22. Brown LD. Endocrine regulation of fetal skeletal muscle growth: impact on future metabolic health. J Endocrinol. 2014;221:R13-29.

23. Brown LD, Rozance PJ, Bruce JL, Friedman JE, Hay Jr WW, Wesolowski SR. Limited capacity for glucose oxidation in fetal sheep with intrauterine growth restriction. Am J Physiol Regul Integr Comp Physiol. 2015;309:R920-8.

24. Limesand SW, Jensen J, Hutton JC, Hay Jr WW. Diminished beta-cell replication contributes to reduced beta-cell mass in fetal sheep with intrauterine growth restriction. Am J Physiol Regul Integr Comp Physiol. 2005;288:R1297-305.

25. Limesand SW, Rozance PJ, Macko AR, Anderson MJ, Kelly AC, Hay Jr WW. Reductions in insulin concentrations and beta-cell mass precede growth restriction in sheep fetuses with placental insufficiency. Am J Physiol Endocrinol Metab. 2013;304:E516-23.

26. Rozance PJ, Hay WW Jr. Pancreatic islet hepatocyte growth factor and vascular endothelial growth factor A signaling in growth restricted fetuses. Mol Cell Endocrinol. 2016. [Epub ahead of print].

27. Thorn SR, Regnault TRH, Brown LD, Rozance PJ, Keng J, Roper M, Wilkening RB, Hay WW, Jr. Friedman JE. Intrauterine growth restriction increases fetal hepatic gluconeogenic capacity and reduces messenger ribonucleic acid translation initiation and nutrient sensing in fetal liver and skeletal muscle. Endocrinology. 2009;150:3021-30

28. Wesolowski SR, Hay WW Jr. Role of placental insufficiency and intrauterine growth restriction on the activation of fetal hepatic glucose production. Mol Cell Endocrinol. 2015. [Epub ahead of print].

29. Yates DT, Green AS, Limesand SW. Catecholamines mediate multiple fetal adaptations during placental insufficiency that contribute to intrauterine growth restriction: lessons from hyperthermic sheep. J Pregnancy. 2011;2011:740408.

30. Yates DT, Clarke DS, Macko AR, Anderson MJ, Shelton LA, Nearing M, Allen RE, Rhoads RP, Limesand SW. Myoblasts from intrauterine growth-restricted sheep fetuses exhibit intrinsic deficiencies in proliferation that contribute to smaller semitendinosus myofibres. J Physiol. 2014:592:3113-25.

31. Whipple AO, Frantz VK. Adenoma of islet cells with hyperinsulinism: a review. Ann Surg. 1935;101:1299-335.

32. Harris DL, Weston PJ, Signal M, Chase JG, Harding JE. Dextrose gel for neonatal hypoglycaemia (the Sugar Babies Study): a randomised, doubleblind, placebo-controlled trial. Lancet. 2013;382:2077-83.

33. Alexandrou G, Skiold B, Karlen J, Tessma MK, Norman M, Aden U, Vanpee M. Early hyperglycemia is a risk factor for death and white matter reduction in preterm infants. Pediatrics. 2010;125:e584-91.

34. McKinlay CJ, Alsweiler JM, Ansell JM, Anstice NS, Chase JG, Gamble GD, Harris DL, Jacobs RJ, Jiang Y, Paudel N, Signal M, Thompson B, Wouldes TA, Yu TY, Harding JE. Neonatal glycemia and neurodevelopmental outcomes at 2 years. N Engl J Med. 2015;373:1507-18.

35. Lilien LD, Pildes RS, Srinivasan G, Voora S, Yeh TF. Treatment of neonatal hypoglycemia with minibolus and intraveous glucose infusion. J Pediatr. 1980;97:295-8.

36. Harris DL, Alsweiler JM, Ansell JM, Gamble GD, Thompson B, Wouldes TA, Yu TY, Harding JE. Outcome at 2 years after dextrose gel treatment for neonatal hypoglycemia: follow-up of a randomized trial. J Pediatr. 2016;170:54-9.
37. Srinivasan G, Pildes RS, Cattamanchi G, Voora S, Lilien LD. Plasma glucose values in normal neonates: a new look. J Pediatr. 1986;109:114-7.

38. Woo HC, Tolosa L, El-Metwally D, Viscardi RM. Glucose monitoring in neonates: need for accurate and non-invasive methods. Arch Dis Child Fetal Neonatal Ed. 2014;99:F153-7.

39. Bennett C, Fagan E, Chaharbakhshi E, Zamfirova I, Flicker J. Implementing a protocol using glucose Gel to treat neonatal hypoglycemia. Nurs Womens Health. 2016;20:64-74

40. Stewart CE, Sage EL, Reynolds P. Supporting 'Baby Friendly': a quality improvement initiative for the management of transitional neonatal hypoglycaemia. Arch Dis Child Fetal Neonatal Ed. 2015. [Epub ahead of print].

41. Beardsall K, Vanhaesebrouck S, Ogilvy-Stuart AL, Vanhole C, Palmer CR, van Weissenbruch M, Midgley P, Thompson M, Thio M, Cornette L, Ossuetta I, Iglesias I, Theyskens C, de Jong M, Ahluwalia JS, de Zegher F, Dunger DB. Early insulin therapy in very-low-birth-weight infants. N Engl J Med. 2008; 359:1873-84.

42. Harris DL, Battin MR, Weston PJ, Harding JE. Continuous glucose monitoring in newborn babies at risk of hypoglycemia. J Pediatr. 2010;157:198-202.

43. Hay Jr WW, Rozance PJ. Continuous glucose monitoring for diagnosis and treatment of neonatal hypoglycemia. J Pediatr. 2010;157:180-2.

44. Harris DL, Weston PJ, Harding JE. Incidence of neonatal hypoglycemia in babies identified as at risk. J Pediatr. 2012;161:787-91.

45. Rozance PJ, Hay Jr WW. Neonatal hypoglycemia-answers, but more questions. J Pediatr. 2012;161:775-6.

46. Boluyt N, van Kempen A, Offringa M. Neurodevelopment after neonatal hypoglycemia: a systematic review and design of an optimal future study. Pediatrics. 2006:117:2231-43.

\section{Submit your next manuscript to BioMed Central and we will help you at every step:}

- We accept pre-submission inquiries

- Our selector tool helps you to find the most relevant journal

- We provide round the clock customer support

- Convenient online submission

- Thorough peer review

- Inclusion in PubMed and all major indexing services

- Maximum visibility for your research

Submit your manuscript at www.biomedcentral.com/submit
) Biomed Central 